\title{
Robust anodic colouring of titanium: effect of electrolyte and
}

\section{colour durability}

Maria Vittoria Diamanti ${ }^{1,2}$, Paola Pozzi ${ }^{1}$, Francesca Randone ${ }^{1}$, Barbara Del Curto ${ }^{1,2}$, MariaPia Pedeferri $^{1,2}$

${ }^{1}$ Politecnico di Milano, Department of Chemistry, Materials and Chemical Engineering

“G. Natta” - Via Mancinelli 7, Milan, Italy

${ }^{2}$ INSTM - Consorzio Interuniversitario di Scienza e Tecnologia dei Materiali - Via G. Giusti

9, Florence, Italy

Corresponding author: Maria Vittoria Diamanti

Email: mariavittoria.diamanti@polimi.it 


\section{ABSTRACT}

An ever growing number of studies involves the production of thin metal oxide films for various purposes, from surface hardening to sensing, to the production of self-cleaning surfaces. Among metallic oxides, titanium dioxide is by far the most investigated: it can be produced by anodic oxidation of titanium in a large variety of electrolytes, either acid, alkaline, or neutral, and within certain limits oxide thickness is linearly proportional to the cell voltage applied. Common industrial plants for titanium anodising use acid electrolytes, which may pose safety issues as well as plant corrosion issues. This article proposes a screening of most common, plus some uncommon, electrolytic solutions used in the anodising of titanium, in order to identify suitable alternatives to acids in the range of neutral electrolytes. Oxides produced in optimal conditions are fully characterised, and treatment robustness is investigated, in order to understand the feasibility of technological transfer. A selection of anodising electrolytes and conditions is finally proposed for applications in architectural and jewellery applications, together with a method for colour restoration in case of wear or mechanical damaging.

Keywords: Anodic oxidation, Electrolyte, Interference colour, Robustness, Titanium, Wear 


\section{INTRODUCTION}

It is well known that the formation of a transparent oxide film on reflective surfaces, such as metallic ones, with thickness ranging from a few nanometres to a few hundreds nanometres, generates the appearance of chromatic effects arising from the interference of light radiation with the oxide [1]. These effects were first investigated and replicated by metal oxidation in early XIX century by Leopoldo Nobili, who is now considered the father of metallochromic art [2].

The physical principles underlying the formation of interference colours by anodic oxidation of titanium and other valve metals have already been described elsewhere [3-6]. These colours are of particular interest for two reasons: the aesthetic quality obtained on oxidised metals, and the possibility to provide an indirect measurement of oxide thickness through the analysis of interference spectra. Yet, the robustness of the anodising treatment becomes vital to ensure brilliant and durable colours with reproducible hues, since in industrial processes parts that do not meet colour match criteria must be rejected $[7,8]$. Moreover, such process should, on one side, avoid alterations to surface finishing, and on the other side ensure to reach the lifetimes required by such applications, especially in presence of potential corrosion and wear issues - e.g., erosion by environmental dust, or prolonged contact with skin in consumer products [9-13]. This is even more important in biomedical applications, where coloured anodised titanium finds use in osteosynthesis devices and dental implants, with an added value of lower ion release and better tolerance by surrounding tissues compared with steel alloys [14,15].

From an industrial point of view, anodic oxidation of titanium does not meet the large diffusion of aluminium, since it is mostly used on biomedical devices and jewellery, going from manual anodising lines to a handicraft connotation $[15,16]$. Titanium anodizing is 
traditionally performed in either acidic or alkaline electrolytes [17-19], requiring a wastewater treatment reactor to be added to the plant. On a research level, other conductive media are being explored, on account of the requisite of reducing the impact of large volumes of chemicals on plants, as well as the impact of their disposal in the environment [20-24]: in fact, acid wastes are considered as hazardous, and need separate and more expensive management. To meet this aim, this work is intended to provide a comparison among different anodic oxidation conditions, focusing on different compositions of electrolytic solution - already mentioned, but to our knowledge not sufficiently explored, in literature [17,25-28] - in order to identify suitable colouring treatments with potential for industrial transfer. To meet this aim, several electrolytes will be considered, either acids or salts, and particular attention will be given to the range of hues achievable and to their saturation.

\section{EXPERIMENTAL}

\section{Materials}

Among most diffuse titanium grades, titanium grade 2 following ASTM classification was used as substrate for anodising. Degreasing with acetone and mechanical polishing down to 1200 grit were employed to clean the metal surface and improve its homogeneity. Anodising was carried out in a series of electrolytes of different composition, concentration and $\mathrm{pH}$. Compositions are summarised in Table 1. To maintain an industrial perspective, all neutral electrolytes chosen do not present issues of availability, nor toxicity; basic prices range are in the order of $30 €$ per $\mathrm{kg}$ (sodium cation) or $75 €$ per $\mathrm{kg}$ (ammonium cation) taking the Sigma-Aldrich online catalogue as reference, as it is one of the largest providers of chemicals [29]. Electrolytes with same anion, or same cation, and different $\mathrm{pH}$ were compared. In all cases, anodising conditions were the following: cell voltages applied ranging between $10 \mathrm{~V}$ and $100 \mathrm{~V}$, measured as potential difference between the titanium anode and an 
activated titanium net used as cathode, and current density of $100 \mathrm{~A} / \mathrm{m}^{2}$; solution temperature and $\mathrm{pH}$ were recorded before and after anodising each sample.

Table 1 - Composition of electrolytes employed in titanium anodising, with color and symbol codes used throughout the article figures

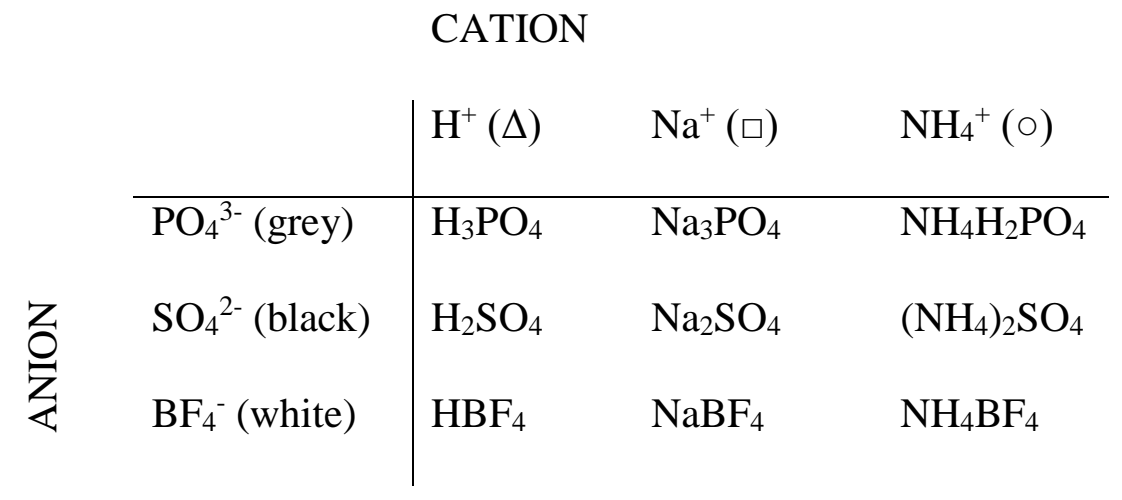

Anodising was also repeated after a second pickling stage applied on already anodised samples: this would represent the possibility of re-colouring from new a damaged surface in case colour is removed accidentally or by wear. In the most appealing electrolytes anodising was repeated on several specimens in the same volume of solution to check if electrolyte consumption would affect the process, and the amount of titanium that could be anodised before needing to refresh the electrolyte.

\section{Characterisation}

Specimens were characterised from the point of view of oxide colour, thickness, and crystalline structure. Colour was measured by spectrophotometry (Konica Minolta CM2600d, light source: D65); values were elaborated by applying the CIELab standard system, in which each colour is represented by a point in the $L a b$ space, where $a^{*}, b^{*}$ and $L^{*}$ correspond to hues ranging from green to red, hues ranging from yellow to blue and lightness ranging from black to white, respectively. Moreover, polar coordinates in each section of the 
Lab colour space at constant lightness identify colour hue, $h$, as angular coordinate and chroma, $C$, as in-plane saturation [30,31]. From reflectance spectra provided by spectrophotometric analyses it was also possible to infer the thickness of the anodic oxides, as already described in previous works $[18,28]$ : curves were fitted by using the refractive index dispersion law given in [16].

\section{Wear resistance}

Finally, the resistance of selected colours to wear was evaluated by means of pin-on-disc tests in synthetic sweat, to replicate the contact with skin and third parts typical of jewels - e.g., other jewels, objects in a drawer, hard surfaces hit during its use. Composition of synthetic sweat is reported in Table 2. The formulation used follows indications from standard EN 1811 [32], except for the use of $\mathrm{KOH}$ instead of $\mathrm{NH}_{4} \mathrm{OH}$ to adjust $\mathrm{pH}$ to values typical of skin. Pinon-disc was performed by means of a six-station AMTI OrthoPOD with an $8 \mathrm{~mm}$ diameter polypropylene pin: $5 \mathrm{~N}$ load was applied for the duration of the test, i.e., 12600 cycles at $0.5 \mathrm{~Hz}$.

Table 2 - Composition of the synthetic sweat employed in wear tests (in percent by weight)

\begin{tabular}{l|l} 
& Concentration \\
\hline NaCl & $0.5 \%$ \\
Urea & $0.1 \%$ \\
Lactic acid & $0.1 \%$ \\
KOH & as needed to \\
& reach pH 5.6
\end{tabular}




\section{Colour restoration}

The last activity presented concerns the actions to undertake when an anodised surface is damaged and colour is partially lost, as a consequence of wear events. One possible solution is to completely remove the colour by chemical etching and anodise the object from new: this process would lead to the perfect restoration of initial surface colour, but it may be time consuming especially if surface finishing was different from simple surface etching - e.g., shot peening, or mirror polishing. In such cases, an alternative process is proposed, which consists of reanodising the coloured object with lower cell voltage compared with the initial one, in order to affect minimally the already coloured zones and restore the colour in the cancelled areas. To meet this aim, suitable voltage combinations were selected - a high voltage, V1, first applied to anodise the object, and a lower voltage, V2, used to recolour the surface after wear. It is of outmost importance to match V1 and V2 based on the resulting hues, which have to be as close as possible. A detailed analysis of possible V1-V2 couples is presented in the Results section.

\section{RESULTS AND DISCUSSION}

\section{Screening of electrolytes}

Given the large number of literature articles and the experience of the research group on the anodising of titanium in acid solutions, the following data will be discussed using as reference electrolytes sulphuric and phosphoric acid. Tetrafluoroborate acid anodising results are not presented since no anodising could be performed even in diluted solutions, owing to the burning of titanium surface.

Concerning oxide growth, the well-known linear trend of increase in oxide thickness with cell voltage [3-6] was observed (Figure 1a); the anodising ratio (AR), i.e., oxide nanometres grown per voltage applied, calculated as the slope of voltage-thickness curves linear 
interpolation are summarised in Table 3. Very similar thickness and AR values are obtained in all electrolytes with the exception of those containing tetrafluoroborate, which appear to produce more pronounced growths. At the highest voltages, thickness obtained in $\mathrm{BF}_{4}^{-}$ containing solutions differed by $30 \%$ to $50 \%$ in excess from thickness obtained in any the other electrolyte. This implies the obtaining of different hues, as shown in Figure 1b, which represents colour coordinates of the oxides with lowest and highest AR, as extracted from spectrophotometric measurements through the software SpectraMagic NX. It can be seen that colour evolves faster for oxides with higher AR: for instance, the first green hue appears on titanium anodised in $\mathrm{NaBF}_{4}$ by applying $40 \mathrm{~V}$, while more than $60 \mathrm{~V}$ are needed in $\mathrm{NH}_{4} \mathrm{H}_{2} \mathrm{PO}_{4}$, which leads to a wider amount of colour hues that can be produced for a given voltage range.
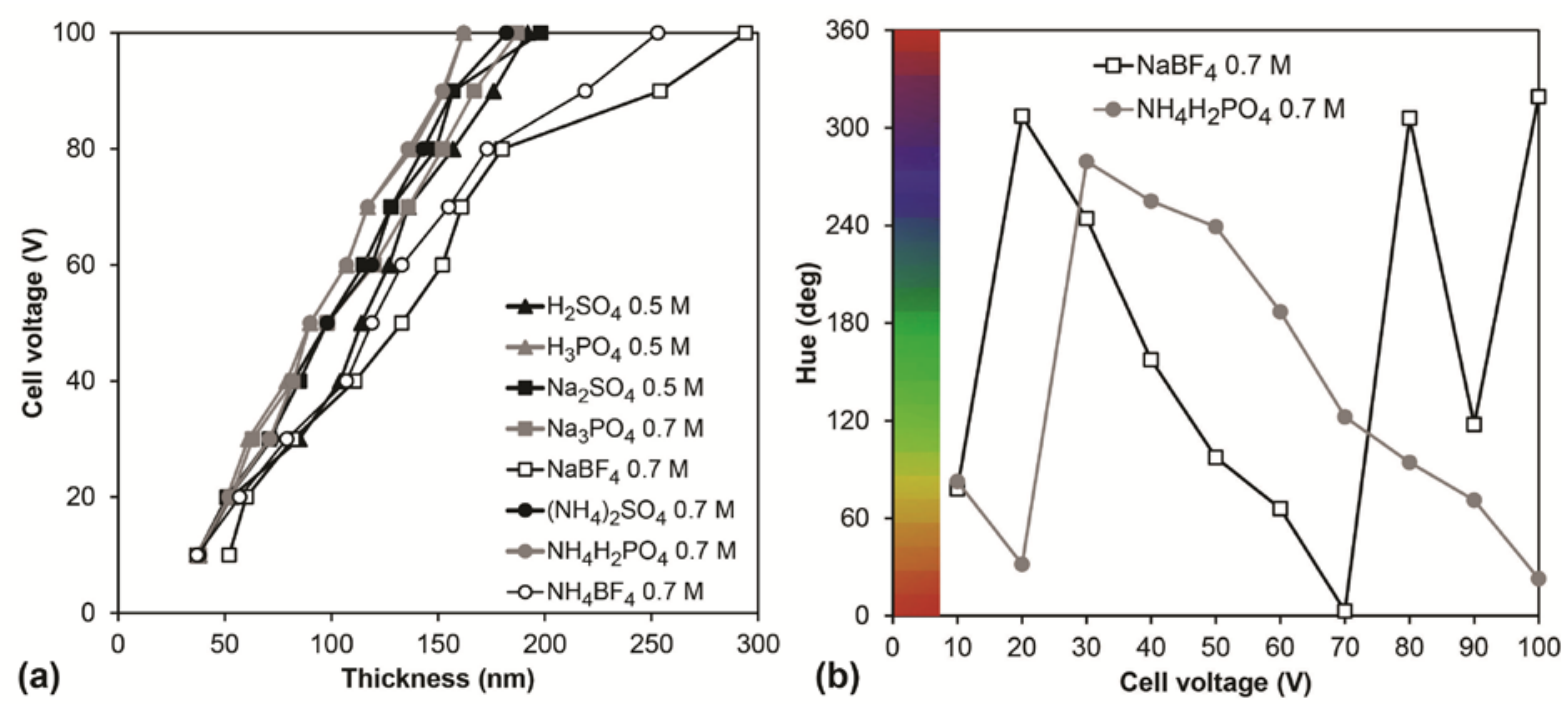

Figure $1-a)$ Oxide growth and b) hue variation, both as a function of cell voltage. 
Table 3 - Linear equations of voltage-thickness curves in the different electrolytes. The slope represents the anodising ratio.

\begin{tabular}{c|llll}
\multicolumn{1}{c|}{ CATION } & & \\
& & $\mathrm{H}^{+}$ & $\mathrm{Na}^{+}$ & $\mathrm{NH}_{4}{ }^{+}$ \\
& $\mathrm{PO}_{4}^{3-}$ & $1.43 \cdot \Delta \mathrm{V}+21 \mathrm{~nm}$ & $1.68 \cdot \Delta \mathrm{V}+17 \mathrm{~nm}$ & $1.38 \cdot \Delta \mathrm{V}+25 \mathrm{~nm}$ \\
$\mathrm{Z}_{\mathrm{O}}^{\mathrm{Z}}$ & $\mathrm{SO}_{4}{ }^{2-}$ & $1.64 \cdot \Delta \mathrm{V}+28 \mathrm{~nm}$ & $1.65 \cdot \Delta \mathrm{V}+18 \mathrm{~nm}$ & $1.54 \cdot \Delta \mathrm{V}+22 \mathrm{~nm}$ \\
& $\mathrm{BF}_{4}^{-}$ & - & $2.54 \cdot \Delta \mathrm{V}+8 \mathrm{~nm}$ & $2.25 \cdot \Delta \mathrm{V}+10 \mathrm{~nm}$
\end{tabular}

Furthermore, it is possible to correlate oxide growth with anodising kinetics, which appears to change from linear $\left(\mathrm{H}_{3} \mathrm{PO}_{4}\right)$ to parabolic $\left(\mathrm{H}_{2} \mathrm{SO}_{4}\right)$. Figure 2a reports the anodising kinetics observed in the electrolytes considered, in terms of time required to reach a given cell voltage: at first, it is interesting to notice how the two acid electrolytes considered correspond to the two extreme behaviours. In fact, anodising is particularly fast in phosphoric acid, while in sulphuric acid the time required to reach a same voltage is double from the very beginning of the process - low cell voltages - and reaches tenfold durations at the maximum imposed voltage of $100 \mathrm{~V}$. This should be ascribed to three contributions: a higher oxide solubility in the more aggressive sulphuric acid; the onset of parasitic oxygen evolution at the anode which takes place in both electrolytes but to a different extent [15,33,34]; and temperature variations induced by an early onset of sparking conditions in $\mathrm{H}_{2} \mathrm{SO}_{4}$, which increases locally the temperature and slows down the whole anodising process [35,36]. All other electrolytes are positioned intermediately, and their behaviour is dependent on both the anion and the cation:

- sulphate based solutions give a slower process on average than phosphate and fluoroborate ones, whose kinetics are extremely similar; 
- ammonium based electrolytes all give an overlapping, fast kinetics, only slightly slower than phosphoric acid, while the presence of sodium largely slows down the process.
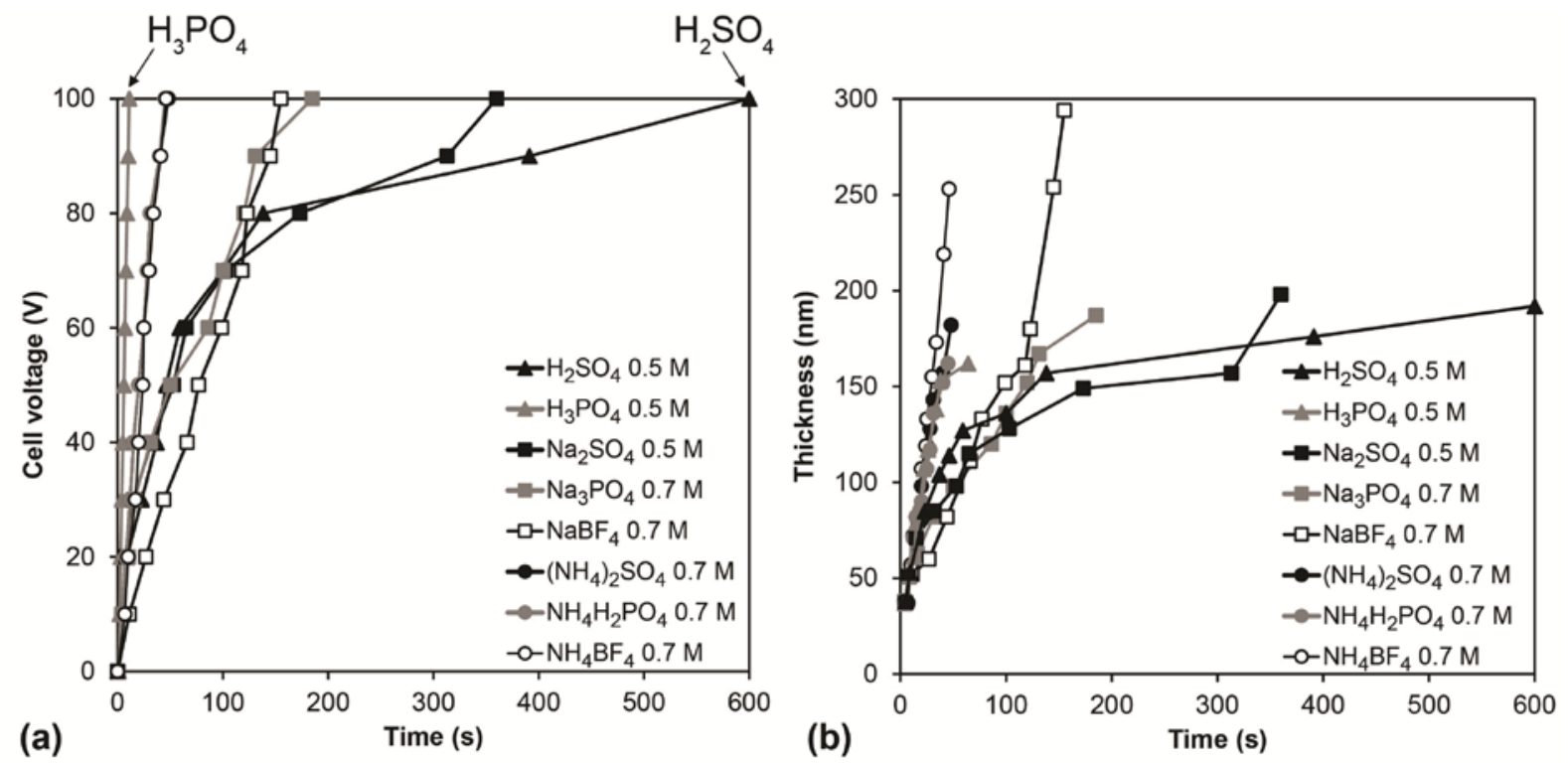

Figure 2 - a) anodising kinetics; b) time required to reach a given thickness.

Given the applied nature of this analysis, which is aimed at defining the most efficient anodising procedure to achieve a large variety of colour hues at the surface of titanium, it is even more important to consider the actual process yield. In fact, anodising kinetics as it is usually given - i.e., as time required to reach the imposed voltage, as this is the parameter that can be set in the process - is not completely representative of how performing is the process. To achieve a particular colour, oxide thickness is the ruling parameter rather than voltage; although there is a linear relationship between the two, AR is not the same for all electrolytes. As a consequence, processes that would appear very similar in terms of time employed are not, owing to the difference in oxide thickness associated with a same cell voltage. This is the case, for instance, of oxides grown in ammonium based electrolytes (Figure 2b): although to reach the highest voltage, $100 \mathrm{~V}$, approximately $50 \mathrm{~s}$ are needed independently on the anion 
associated, oxide thickness is much higher in fluoroborate electrolyte. This means that in this solution the time required to achieve a particular colour (thickness) is lower than in ammonium sulphate or phosphate, which makes it more performing.

Finally, a further consideration was drawn on the quality of colours obtained. While hues are important to define the range of colours available on titanium, another crucial parameter is colour saturation, which is represented in Figure 3 in the form of chroma - i.e., in-plane saturation at a given lightness. Lightness itself was not considered as it strongly depends on substrate pretreatments and finishing. As can be noticed, phosphate containing acid electrolytes $\left(\mathrm{H}_{3} \mathrm{PO}_{4}, \mathrm{NH}_{4} \mathrm{H}_{2} \mathrm{PO}_{4}\right)$ cause the formation of colours with low saturation, which is detrimental to the final results: for this reason, they were discarded in subsequent investigations. On the contrary, in neutral to slightly alkaline conditions a higher saturation is achieved.

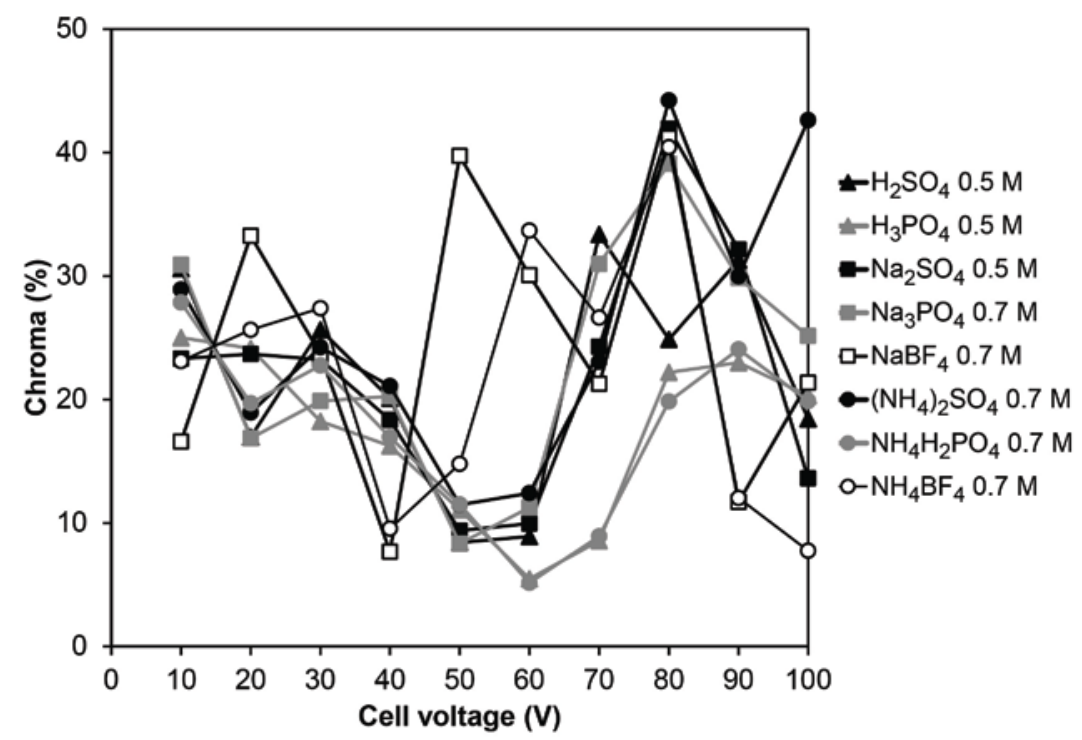

Figure 3 - Chroma (colour intensity) of anodised specimens, as a function of cell voltage. 


\section{Colouring process evaluation in selected electrolytes}

After this initial screening, the more promising electrolytes were further analysed, and repeatability tests were performed by anodising 15 samples at $100 \mathrm{~V}$ in each solution, consecutively and without substituting the electrolyte. Results are presented in Figure 4: colours are reproduced in the $\mathrm{a}^{*}$-b* section of the CIELab sphere, and the range of hues obtained is highlighted in terms of maximum hue angle difference among the replicates. Moreover, anodising time was also recorded and the variation indicated in the table integrated in Figure 4.

While fluoroborate containing electrolytes tend to produce highly saturated colours, as also evidenced in Figure 3, the process lacks reproducibility: hues can differ even by $60^{\circ}$, which is extremely large, and not acceptable industrially when several workpieces must be realised with same colour. On the contrary, the best reproducibility is presented by titanium anodised in sulphate based solutions, and in particular $\mathrm{H}_{2} \mathrm{SO}_{4}$, as already noticed in previous works [16]. Unfortunately, this process is the longest (Figure 2): while for low voltages it is competitive with the other electrolytes, above $80 \mathrm{~V}$ anodising kinetics is slowed down by the onset of dielectric breakdown [35,36]. Moreover, the range of hues is more limited in sulphate based electrolytes compared with fluoroborate ones, especially in $\left(\mathrm{NH}_{4}\right)_{2} \mathrm{SO}_{4}$, which - on the other hand - appears to be the one with closest performances to fluoroborate solutions in terms of anodising time.

It is therefore clear that $\mathrm{NH}_{4} \mathrm{BF}_{4}$ presents the best compromise of colour hues ad saturation with high anodising kinetics, which would allow to set an economic process with potential for industrial transfer. 


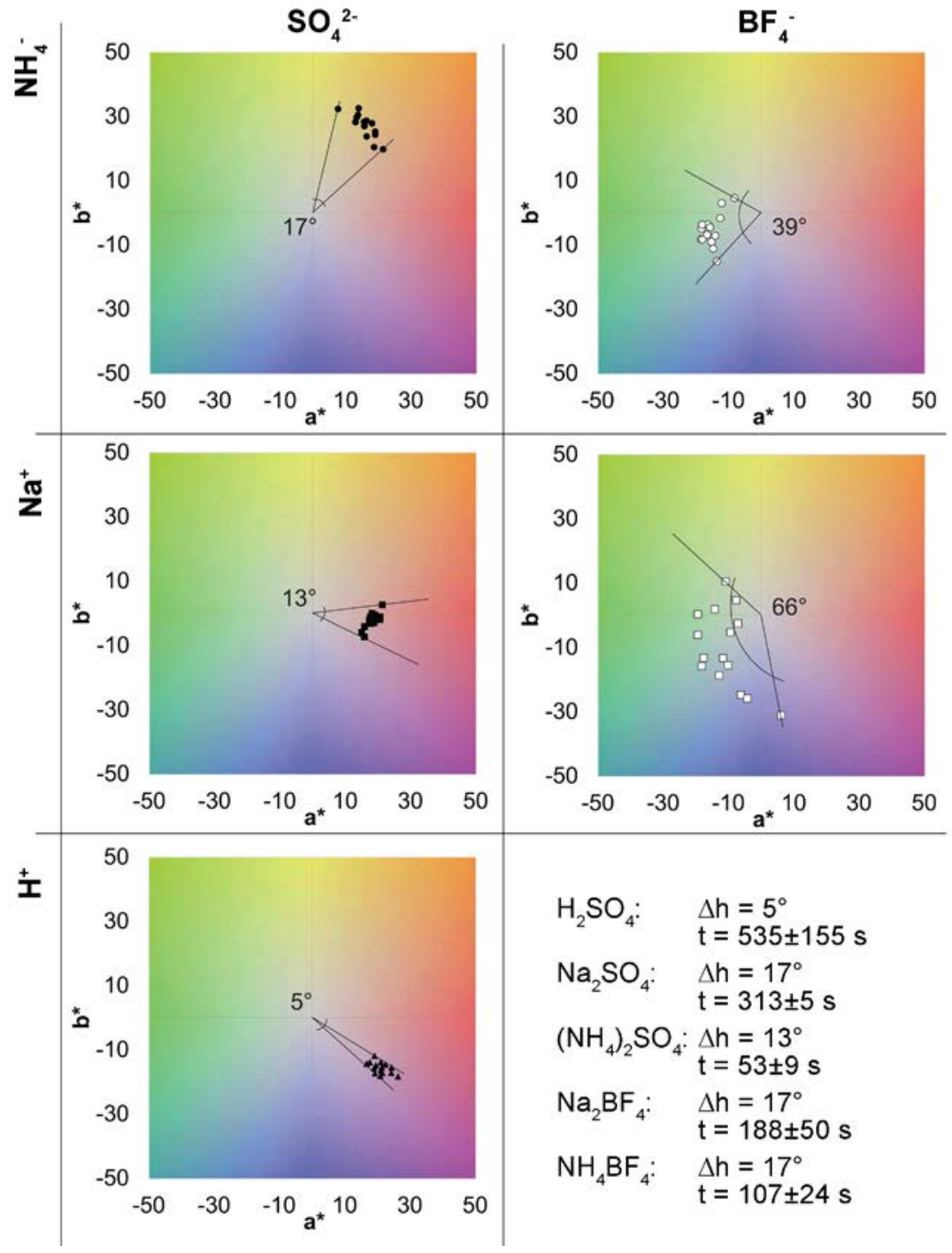

Figure $4-a^{*}-b *$ diagrams reporting colour coordinates of 15 replicates of titanium samples anodised at $100 \mathrm{~V}$ in different electrolytes; maximum hue variation

Yet, although repeatability is better than that observed in the case of $\mathrm{NaBF}_{4}$, this parameter still needs to be improved for those processes where perfect colour reliability is required, for instance in architectural applications where tens of cladding panels are exposed side by side. For this reason, such electrolyte was further investigated to develop a process that could allow to combine all necessary features: low anodising time, high repeatability of colour hue, high saturation and wide range of achievable hues. 
Figure 5 reports hues and thickness of titanium anodised in $\left(\mathrm{NH}_{4}\right)_{2} \mathrm{SO}_{4}$, compared with $\mathrm{NH}_{4} \mathrm{BF}_{4}$. To reach the same range of hues, i.e., oxide thickness, a larger cell voltage range must be spanned, reaching $140 \mathrm{~V}$ to have the same thickness obtained in $\mathrm{NH}_{4} \mathrm{BF}_{4}$ at $100 \mathrm{~V}$.

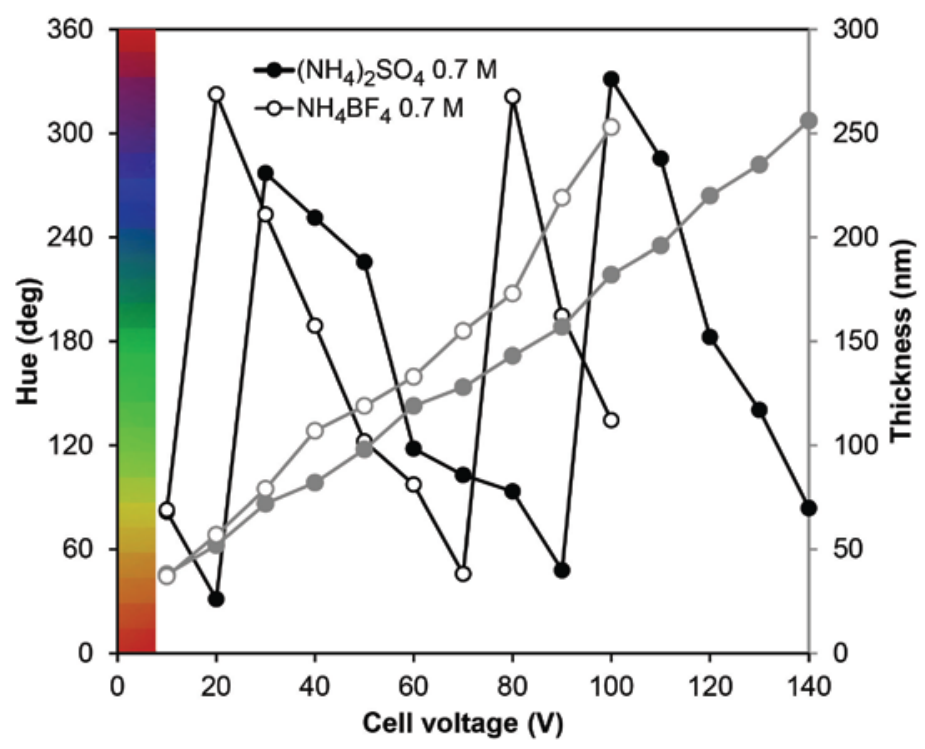

Figure 5 - Oxide hue (black curves) and thickness (grey lines) as a function of cell voltage for $\left(\mathrm{NH}_{4}\right)_{2} \mathrm{SO}_{4}$ (full circles) and $\mathrm{NH}_{4} \mathrm{BF}_{4}$ (empty circles) electrolytes.

To conclude this evaluation and optimisation of process characteristics, it is possible to state that $\left(\mathrm{NH}_{4}\right)_{2} \mathrm{SO}_{4}$ and $\mathrm{NH}_{4} \mathrm{BF}_{4}$ represent the best electrolytes to obtain wide ranges of colours with high saturation, with optimised high anodising kinetics. The former is suggested when ideal reproducibility is required, but larger voltages are needed to increase the range of colours, which increases the equipment costs: as already proposed, this could be suitable for architectural panels. Conversely, the latter allows to achieve the same colour spectrum with lower voltages, at the expense of colour reproducibility: the higher colour saturation makes this process particularly suitable for seminoble jewels production. Both of them present similar cost and no toxicity to the environment, thus eliminating environmental risks associated with waste management. 


\section{Evaluation of wear resistance}

The last research step involved the evaluation of the oxide durability, especially meant for jewels, which may be in direct and sliding contact with other surfaces. Therefore, this evaluation was performed on the most suitable treatment identified, i.e., anodising in $\mathrm{NH}_{4} \mathrm{BF}_{4}$, and on our internal reference treatment, i.e., anodising in $\mathrm{H}_{2} \mathrm{SO}_{4}$. The surfaces of selected samples, anodised at $25 \mathrm{~V}, 60 \mathrm{~V}$ and $90 \mathrm{~V}$, were subjected to pin-on-disc tests reproducing 8 months of wear in an environment of synthetic sweat. The choice of anodising voltages relies on the possibility of testing three ranges of oxide thickness and colours, as summarised in Table 4. Tests were performed qualitatively, in order to point out possible colour alterations. Overall colour variation was also calculated based on CIELab recommendations:

$$
\Delta E_{i v s i-1}=\sqrt{\left(a^{*}{ }_{i}-a^{*}{ }_{i-1}\right)^{2}+\left(b^{*}{ }_{i}-b^{*}{ }_{i-1}\right)^{2}+\left(L^{*}{ }_{i}-L^{*}{ }_{i-1}\right)^{2}}
$$

Table 4 - Thickness and associated colour of samples subjected to pin-on-disc tests. CIELab coordinates are given before and after pin-on-disc tests.

\begin{tabular}{|c|c|c|c|c|}
\hline Voltage & Thickness & Colour & $a^{*}$ CIELab & $\mathrm{b}^{*}$ CIELab \\
\hline$(\mathrm{V})$ & $(\mathrm{nm})$ & & before after & before after \\
\hline
\end{tabular}

\begin{tabular}{ccccccccc}
\hline & 25 & 75 & Blue & 5 & 3 & -29 & -28 & 1.6 \\
$\mathrm{NH}_{4} \mathrm{BF}_{4}$ & 60 & 150 & Gold & 5 & 6 & 22 & 21 & 1.3 \\
& 90 & 220 & Green & -11 & -9 & 3 & 8 & 6.1 \\
\hline $\mathrm{H}_{2} \mathrm{SO}_{4}$ & 60 & 120 & Light yellow & -4 & -4 & 9 & 10 & 0.6 \\
& 90 & 185 & Pink & 15 & 13 & -12 & -14 & 3.0
\end{tabular}


In all cases a prolonged sliding caused a partial discolouration of the metal surface corresponding to the pin trajectory, which may result either in the disappearance of the oxide or to its thinning, and therefore in the evolution of colour to hues associated to lower thicknesses (Figure 6). For instance, oxides produced at $90 \mathrm{~V}$ do not disappear completely, as in the case of $25 \mathrm{~V}$, but rather change colour, passing from green or pink to a golden hue. This variation is only partially acknowledged by the $\Delta \mathrm{E}$ calculated, whose value is mediated over an area of approximately $1.2 \mathrm{~cm}$ diameter, which therefore includes a consistent part of the pristine oxide. Moreover, the oxide produced at $60 \mathrm{~V}$ appears to be the least affected, as also proved by the lowest $\Delta \mathrm{E}$ : this may be ascribed not to a higher durability, but rather to the slower change in hue in this portion of cell voltages, where a light yellow colour is preceded by a light green and followed by a stronger gold hue, therefore slight changes are less noticeable.
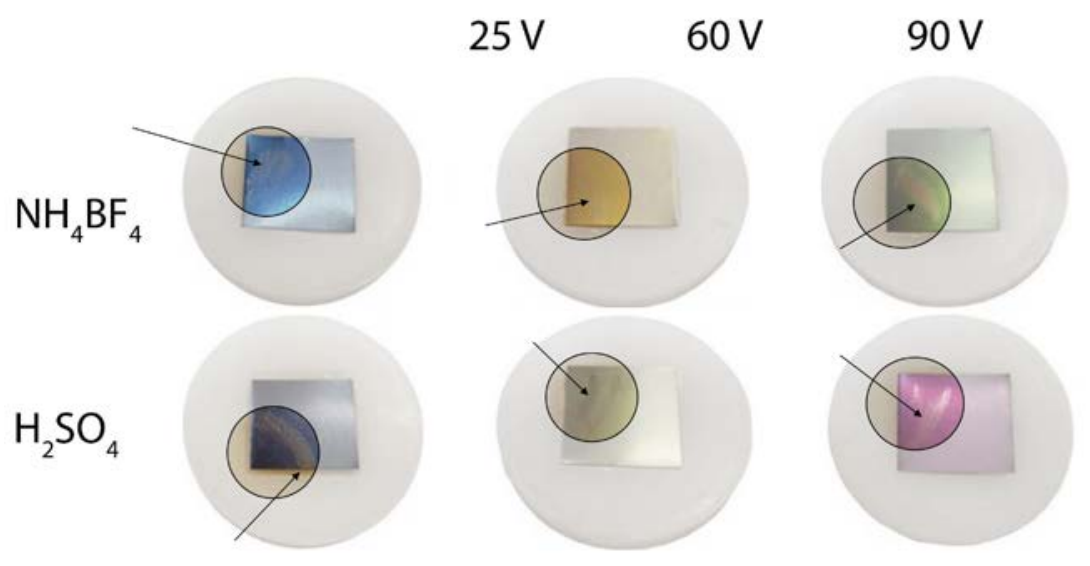

Figure 6 - Surface appearance of specimens after wear tests: traces of pin sliding causing colour change or disappearance are highlighted.

More generally, results indicated a higher resistance to wear on samples anodised in $\mathrm{NH}_{4} \mathrm{BF}_{4}$, whose colour was maintained more uniform, while those anodised in $\mathrm{H}_{2} \mathrm{SO}_{4}$ showed a clearer trace of the polymeric pin on the surface. This tendency can be quantified by macroscopic 
colour measurements, whose spot is larger than the wear trace, therefore an only partial discolouration emerges from the decrease in colour intensity generally observed, and more evidently in samples anodised in $\mathrm{H}_{2} \mathrm{SO}_{4}$ (Table 4).

A recolouration strategy is therefore required, aimed at refilling surface colour in the missing points.

\section{Colour restoration}

As anticipated in the Experimental section, complete recolouring can be considered with related advantages and drawbacks: here we present an alternative process, based on the reanodising of the coloured object, with lower cell voltage compared with the initial one, in order to affect minimally the already coloured zones and restore the colour in the cancelled areas. To meet this aim, a chromatic scale was built in $\mathrm{NH}_{4} \mathrm{BF}_{4}$, with more experimental points, in order to identify couples of $\mathrm{V}_{\mathrm{a}}$ - i.e., initial voltage, corresponding to the jewel hue - and $\mathrm{V}_{\mathrm{b}}$, to be applied as correction and leading to similar hue. Restrictions are as follow:

- $\quad V_{a}>V_{b}$, in order to avoid complete colour changes to the object and maintain the initial hue as unaltered as possible: in fact, even the application of same V1 voltage in a second anodising step would cause a change in surface colour;

- $\mathrm{h}_{\mathrm{Va}} \approx \mathrm{h}_{\mathrm{Vb}}$, to fill the missing points with colour similar to the original one.

First, a close-voltage approach was chosen, considering the re-anodising of samples at voltages only slightly lower than $\mathrm{V}_{\mathrm{a}}$. A series of samples was anodised with voltages ranging from 3 to $100 \mathrm{~V}$ : each sample was anodised with incremental voltages $\mathrm{V}_{\mathrm{i}}=\mathrm{V}_{\mathrm{i}-1}+3 \mathrm{~V}$, and the colour difference between $\mathrm{V}_{\mathrm{i}}$ and $\mathrm{V}_{\mathrm{i}-1}$ (which would act as $\mathrm{V}_{\mathrm{a}}$ and $\mathrm{V}_{\mathrm{b}}$, respectively) was calculated on the basis of CIELab colour coordinates as previously described. This process would provide the recolouring of the cancelled parts by applying a voltage as close as possible to, but still lower than, the initial one. Since human eye is not able to 
perceive colour variations below $\Delta \mathrm{E}=3$, a threshold of acceptability equal to $\Delta \mathrm{E}=3$ was chosen, and an extended range of semi-acceptability of 7, which correspond to negligible to slightly perceivable variations.

Unfortunately, this approach did not lead to significant results. In fact, only one colour lies in the range of acceptability, i.e., light blue obtained at $35 \mathrm{~V}$, as represented by the black circle in Figure 7 (the other black circle lies in the range of almost uncoloured titanium, below $9 \mathrm{~V}$ ). Moreover, few hues have similar colours in the close surroundings: these are represented by grey circles with solid black line, and refer mostly to pale hues in the $40 \mathrm{~V}$ to $60 \mathrm{~V}$ range (light green to yellow/gold). Finally, above $93 \mathrm{~V}$ very similar green hues are produced with different saturation, which gives a semi-acceptable $\Delta \mathrm{E}$.

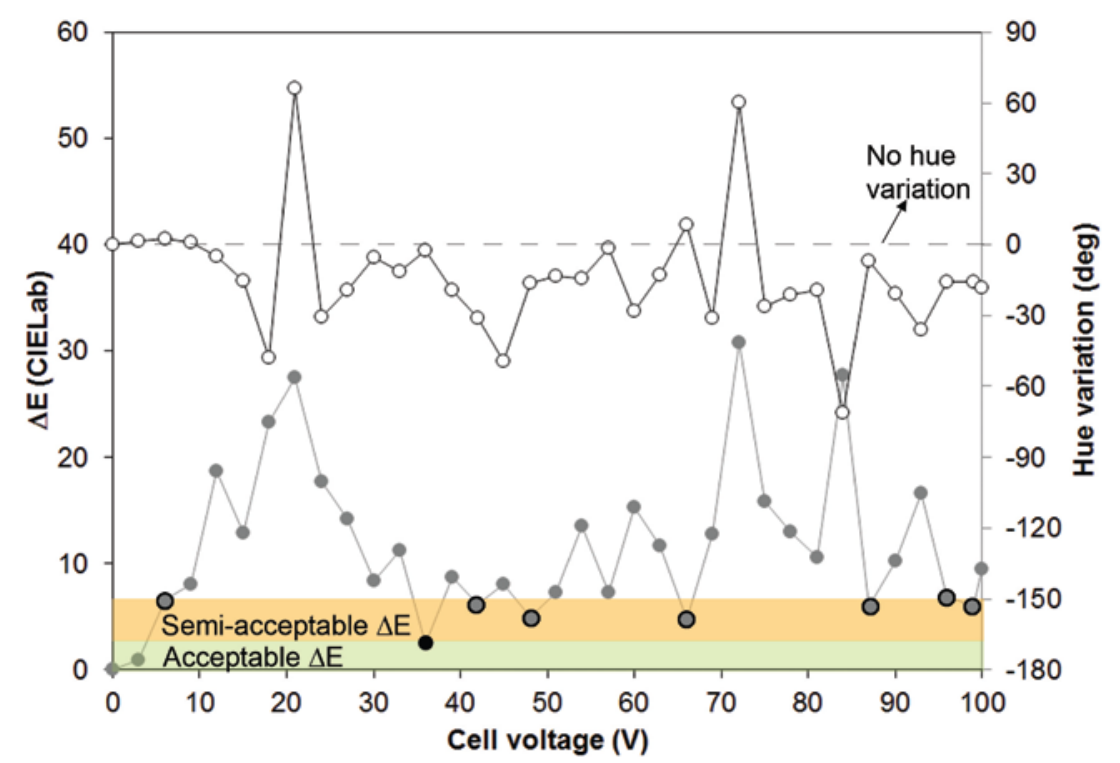

Figure 7 - Differences in colour ( $\Delta \mathrm{E}$, grey circles) and hue (white circles) between titanium surfaces anodised with $3 \mathrm{~V}$ difference. Threshold for identical hues (dashed line) and ranges of acceptable or semi-acceptable colour differences (maximum $\Delta \mathrm{E}=3$ and 7, respectively) are also reported. Black circles represent acceptable couples of $V_{a}$ and $V_{b}$, where $V_{b}=V_{a}$ $3 \mathrm{~V}$, grey circles with black solid line represent tolerable couples of $\mathrm{V}_{\mathrm{a}}$ and $\mathrm{V}_{\mathrm{b}}$. 
A new approach was considered, consisting of choosing similar hues in the whole range of anodising. The hue-voltage diagram was used to meet this aim. The adopted logic process is shown in Figure 8. Several high voltage hues, ranging from pink to blue, to green and yellow, find counterparts in the low voltage region, although in some cases saturation is different (e.g., for $\mathrm{V}_{\mathrm{a}}=93 \mathrm{~V}$ and $\mathrm{V}_{\mathrm{b}}=47 \mathrm{~V}$ have the same green hue but at $47 \mathrm{~V}$ chroma is only half).

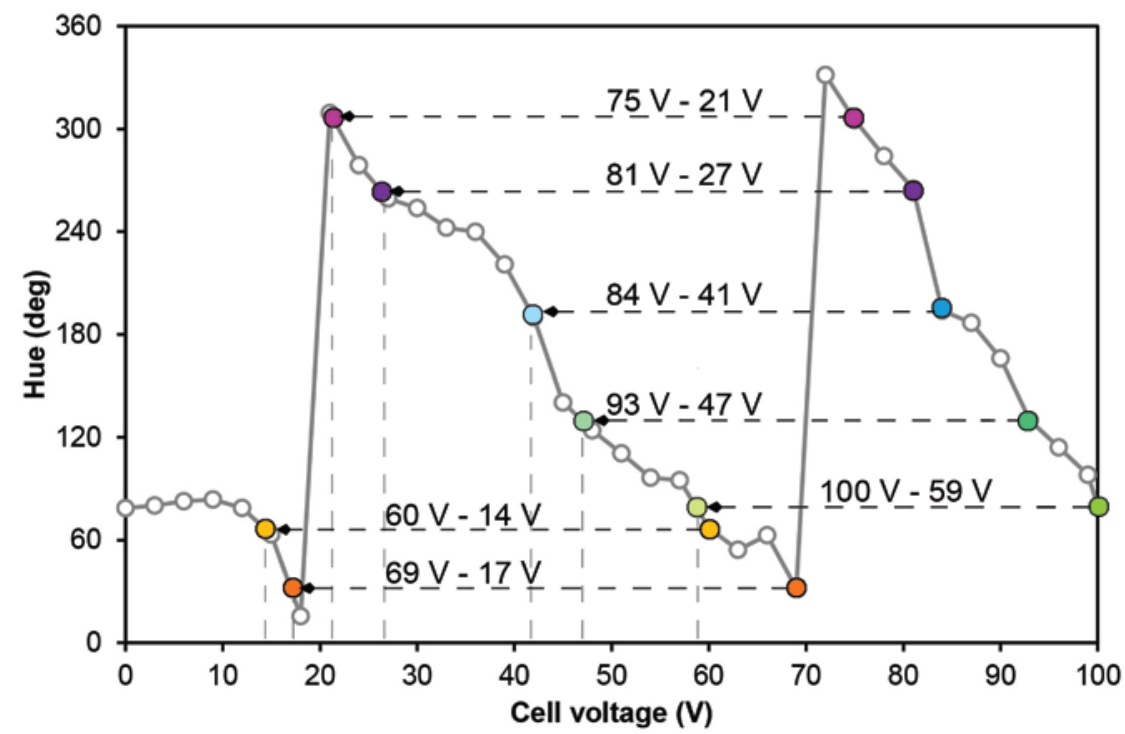

Figure 8 - Hue evolution with cell voltage and identification of $V_{a}, V_{b}$ couples with same hue for re-anodising.

Figure 9 reports the colours obtained by anodising half sample at different values of $\mathrm{V}_{\mathrm{a}}$ (black symbols) and by re-anodising it at corresponding $\mathrm{V}_{\mathrm{b}}$ : both the colours of the previously anodised surface (grey symbols) and of the blank one (white symbols) are shown, representing in a jewel the recolouring of still coloured portions and of damaged ones, respectively. It is interesting to notice how the differences in colour between original surface $\left(\mathrm{V}_{\mathrm{a}}\right)$ and twice-coloured one $\left(\mathrm{V}_{\mathrm{a}}+\mathrm{V}_{\mathrm{b}}\right)$ may be non-negligible, but the final colours appearing at the same surface (twice-coloured portions and recoloured defects, $\mathrm{V}_{\mathrm{b}}$ ) are very similar in 
most cases. The only exception is represented by recolouring the gold hue $(60 \mathrm{~V})$, whose final result would present a well perceivable difference in hues on the same surface.

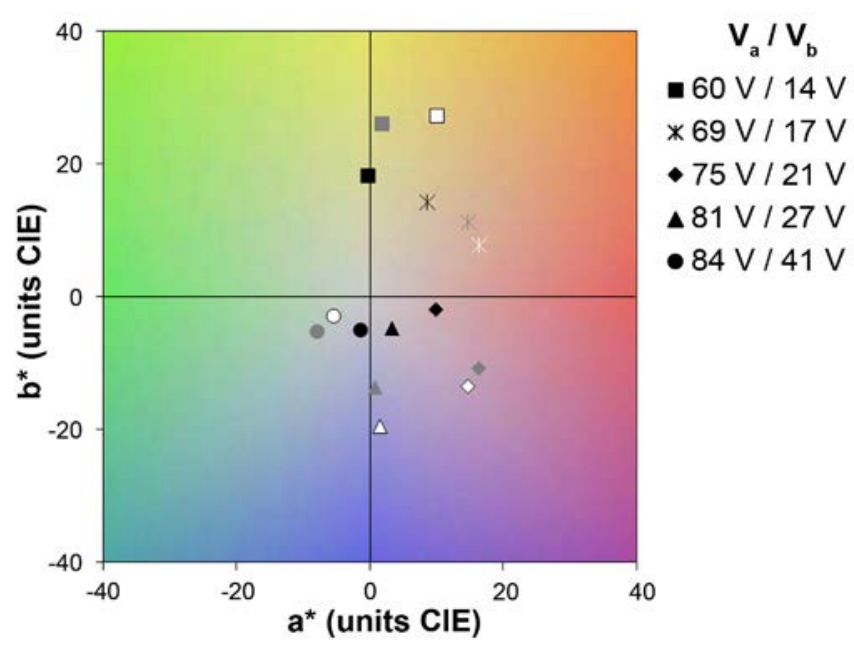

Figure 9 - Results of recolouring: anodising at $\mathrm{V}_{\mathrm{a}}$ (black symbols), re-anodising the coloured surface at $\mathrm{V}_{\mathrm{b}}$ (grey symbols) and anodising a blank surface at $\mathrm{V}_{\mathrm{b}}$.

From these results it is possible to state that this procedure ensure the acceptability of recolouring: a good similarity between original colour and recoloured surface is reached in all ranges of hues (yellow, green, pink and blue), and defects are well concealed with colour well adherent to the rest of the recoloured surface. Yet, in the light of an application in the restoration of anodised titanium seminoble jewellery, it is important to choose carefully not only the recolouring voltage $\mathrm{V}_{\mathrm{b}}$, but also - if possible, in the design phase - the voltage $\mathrm{V}_{\mathrm{a}}$. In fact, similar hues may be more or less difficult to restore, as in the example of gold colours obtained at $60 \mathrm{~V}$ and $69 \mathrm{~V}$ : in the latter case recolouring is effective, while at $60 \mathrm{~V}$ it leads to mismatches in the final result. 


\section{CONCLUSION}

This article presented an investigation of anodising techniques with potential for technological transfer, analysing the pros and cons of different electrolytes - ease of use, reproducibility of colour, range of hues and saturation obtainable. Considering the potential for technological transfer of the alternatives proposed, the use of neutral electrolytes may easily replace current technology based mostly on $\mathrm{H}_{2} \mathrm{SO}_{4}$ with no investment costs; on new plants this would allow easier handling and lower personnel risks, higher durability of plant materials, and reduction of waste management costs upon the elimination of highly acid solutions.

Two electrolytes were selected for different applications, both showing no toxicity issues. $\left(\mathrm{NH}_{4}\right)_{2} \mathrm{SO}_{4}$, a common fertilizer, was selected for architectural applications of anodized titanium, where colour tolerance is very strict owing to the need of exposing several components with identical colour close to one other. $\mathrm{NH}_{4} \mathrm{BF}_{4}$ is proposed for seminoble jewels production, where saturation is crucial and there is more tolerance on hues of single

pieces. In the latter case, also resistance to sliding contact was evaluated to simulate the jewel wear during use; and a recolouring strategy is proposed, to allow easy restoration of the scratched or worn parts without replicating other surface finishing processes on the whole object.

\section{ACKNOWLEDGEMENTS}

The authors would like to acknowledge INSTM and the Lombardy region for financially supporting this research work in the frame of project SIMQUI. 


\section{REFERENCE LIST}

[1] U.R. Evans, The colours due to thin films on metals. Proc. Royal Soc. London Series A 107 (1925) 228-237.

[2] C. Oleari, Color in optical coatings. In: A. Piegari, F. Flory, Optical Thin Films and Coatings: From Materials to Applications. Cambridge, England: Woodhead Publishing Limited, 2013, pp. 391-424

[3] E. Gaul, Colouring titanium and related metals by electrochemical oxidation. J. Chem. Educ. 70 (1993) 176-179.

[4] S. Van Gils, P. Mast, E. Stijns, H. Terryn, Colour properties of barrier anodic oxide film on aluminium and titanium studied with total reflectance and spectroscopic ellipsometry. Surf. Coat. Technol. 185 (2004) 303-310.

[5] M.V. Diamanti, B. Del Curto, V. Masconale, C. Passaro, M. P. Pedeferri, Anodic coloring of titanium and its alloy for jewels production. Color Res. Appl. 37 (2012) 384-390.

[6] J.F. Vanhumbeeck, J. Proost, Current understanding of Ti anodization: functional, morphological, chemical and mechanical aspects. Corros. Rev. 27 (2009) 117-194. [7] R.S. Berns, Deriving instrumental tolerances from pass-fail and colorimetric data. Color Res. Appl. 21 (1996) 459-472.

[8] Y. Koishi, N. Tanoue, H. Matsumura, M. Atsuta, Colour reproducibility of a photoactivated prosthetic composite with different thicknesses. J. Oral Rehab. 28 (2001) 799-804. [9] E. Vermesse, C. Mabru, L. Arurault, Surface integrity after pickling and anodization of Ti6Al-4V titanium alloy. Appl. Surf. Sci. 285 (2013) 629-637.

[10] S. Colin, E. Beche, R. Berjoan, H. Jolibois, A. Chambaudet, An XPS and AES study of the free corrosion of Cu-, Ni- and Zn- based alloys in synthetic sweat. Corros. Sci. 41 (1999) 1051-1065. 
[11] Fonseca, C., Vaz, F., Barbosa, M.A., Electrochemical behaviour of titanium coated stainless steel by r.f. sputtering in synthetic sweat solutions for electrode applications. Corros. Sci. 46 (2004) 3005-3018.

[12] X. Dai, K. Zhang, C. Tang, Friction and wear of pivot jewel bearing in oil-bath lubrication for high rotational speed application. Wear 302 (2013) 1506-1513.

[13] I. Milošev, T. Kosec, Metal ion release and surface composition of the $\mathrm{Cu}-18 \mathrm{Ni}-20 \mathrm{Zn}$ nickel-silver during 30 days immersion in artificial sweat. Appl. Surf. Sci. 254 (2007) 644652.

[14] Y. Hedberg, K. Midander, I.O. Wallinder, Particles, Sweat, and Tears: A Comparative Study on Bioaccessibility of Ferrochromium Alloy and Stainless Steel Particles, the Pure Metals and Their Metal Oxides, in Simulated Skin and Eye Contact. Int. Environ. Assess. Manag. 6 (2010) 456-468.

[15] M.V. Diamanti, B. Del Curto, MP. Pedeferri, Anodic oxidation of titanium: from technical aspects to biomedical applications. J. Appl. Biomater. Biomech. 9 (2011) 55-69. [16] M.V. Diamanti, B. Del Curto, V. Masconale, C. Passaro, M. P. Pedeferri, Anodic coloring of titanium and its alloy for jewels production. Color Res. Appl. 37 (2012) 384-390. [17] Y.-T. Sul, C.B. Johansson, Y. Jeong, T. Albrektsson, The electrochemical oxide growth behaviour on titanium in acid and alkaline electrolytes. Med. Eng. Phys. 23 (2001) 329-346. [18] J.-L. Delplancke, M. Degrez, A. Fontana, R. Winand, Self-colour anodising of titanium. Surf. Technol.16 (1982) 153-162.

[19] J. Moon, M. Kemell, B. Park, A. Suominen, et al., The correlation between the interference colour and growth procedure of anodic titanium dioxide nanotube arrays. Color. Technol. 130 (2013) 1-7.

[20] C. Rosenstein, Chemical analysis plating solutions. Metal Finish. 97 (1999) 516-562. 
[21] M. Tomkiewicz, Environmental aspects of electrodeposition. In: M. Schlesinger, M Paunovic eds, Modern Electroplating. Hoboken, NJ: John Wiley \& Sons, 2010, pp. 555-572. [22] F. Testa, D. Styles, F. Iraldo, Case study evidence that direct regulation remains the main driver of industrial pollution avoidance and may benefit operational efficiency. J. Cleaner Prod. 21 (2012) 1-10.

[23] J.M. Chimenos, A.I. Fernaádez, A. Hernández, L. Haurie, F. Espiell, C. Ayora, Optimization of phosphate removal in anodizing aluminium wastewater. Water Res. 40 (2006) 137-143.

[24] T. Yoshioka, T. Kameda, M. Miyahara, M. Uchida, T. Mizoguchi, A. Okuwaki, Removal of tetrafluoroborate ion from aqueous solution using magnesium-aluminum oxide produced by the thermal decomposition of a hydrotalcite-like compound. Chemosphere 69 (2007) 832835.

[25] L. Bartlett, An unusual phenomenon observed when anodising CP titanium to produce coloured surfaces for jewellery and other decorative uses. Optics Laser Technol. 38 (2006) 440-444.

[26] W. Simka, A. Sadkowski, M. Warczak, A. Iwaniak, G.Dercz, J. Michalska, A. Maciej, Characterization of passive films formed on titanium during anodic oxidation. Electrochim. Acta 56 (2011) 8962-8968.

[27] G. Jerkiewicz, H. Strzelecki, A. Wieckowski, A new procedure of formation of multicolor passive films on titanium: compositional depth profile analysis. Langmuir 12 (1996) 1005-1010.

[28] M.V. Diamanti, P. Garbagnoli, B. Del Curto, MP. Pedeferri, On the growth of thin anodic oxides showing interference colors on valve metals. Curr. Nanosci. 11 (2015) 307-316. [29] http://www.sigmaaldrich.com/technical-service-home/product-catalog.html last accessed on November $10^{\text {th }}, 2015$. 
[30] R.W.G. Hunt, The reproduction of colour. Tolworth, England: Fountain Press, 1987.

[31] G. Wyszecki, W.S. Stiles, Colour science. New York: John Wiley \& Sons, 1982.

[32] EN 1811. Reference test method for release of nickel from products intended to come into direct and prolonged contact with the skin. British-Adopted European Standard, 1999. [33] Z. Liu, X. Liu, U. Donatus, G.E. Thompson, P. Skeldon, Corrosion Behaviour of the Anodic Oxide Film on Commercially Pure Titanium in NaCl Environment. Int. J.

Electrochem. Sci. 9 (2014) 3558-3573.

[34] B.J. Hwang, J.R. Hwang, Kinetic model of anodic oxidation of titanium in sulphuric acid. J. Appl. Eletrochem. 23 (1993) 1056-1062.

[35] H. Habazaki, M. Uozumi, H. Konno, K. Shimizu, P. Skeldon, G.E. Thompson, Crystallization of anodic titania on titanium and its alloys. Corros. Sci. 45 (2003) 2063-2073. [36] M.V. Diamanti, M.P. Pedeferri, Effect of anodic oxidation parameters on the titanium oxides formation. Corros. Sci. 49 (2007) 939-948. 